\title{
A construção de cidades saudáveis: uma estratégia viável para a melhoria da qualidade de vida?
}

\author{
Building healthy cities: a strategy \\ to improve the quality of life?
}

Jaime Rabelo Adriano 1

Gustavo Azeredo Furquim Werneck 2

Max André dos Santos 3

Rita de Cássia Souza 4

\footnotetext{
1 Escola de Saúde de Minas Gerais - Fundação Ezequiel Dias (ESMIG/FUNED) Núcleo Cidade Saudável. Av. Augusto de Lima 2061, Barro Preto, 30190-002 Belo Horizonte, MG. esmigbib@net.em.com.br 2 Universidade Federal de Minas Gerais - Núcleo de Estudos em Saúde Coletiva e Nutrição - UFMG/ NESCON

3 Universidade Federal de Minas Gerais - Núcleo de Investigação Social e Epidemiológica

4 Escola de Saúde de Minas Gerais - Fundação Ezequiel Dias (ESMIG/FUNED).

Núcleo Cidade Saudável
}

Abstract This paper aims at discussing the importance of the Healthy City Movement as a strategy to improve the quality of life of the population. From the movement's present context both in the Brazil and in the world, a pilot experiment carried out in 1996-1998, in the cities of Dionísio and São José do Goiabal, in the Brazilian state of Minas Gerais, is presented and analyzed. Taking interdisciplinarity, intersectorality and participation as basic assumptions, the strategic planning methodology proposed by Carlos Matus was used to develop an action plan to face priority problems in the municipalities. The active participation of community groups was encouraged so that at the end of the process this methodology could be assimilated by and incorporated to the routine of municipal administrations. This paper shows some preliminary results and discusses the advantages and constraints of this process.

Key words Healthy Municipality/City; Health Promotion; Quality of Life
Resumo Este artigo pretende discutir a importância do Movimento Cidades Saudáveis como uma estratégia para melhoria da qualidade de vida da população. A partir da contextualização do movimento no mundo e no Brasil, uma experiência-piloto desenvolvida no período de 1996-1998, nos municípios mineiros de Dionísio e São José do Goiabal é apresentada e analisada. Tomando como pressupostos básicos a interdisciplinaridade, intersetorialidade e a participação, foi utilizada a metodologia de planejamento estratégico situacional (PES), proposta por Carlos Matus, para elaborar um plano de ação para o enfrentamento de problemas prioritários nos municípios. A participação ativa de grupos da comunidade foi estimulada de modo a permitir que ao final do processo essa metodologia pudesse ser assimilada e incorporada ao cotidiano das administrações municipais. O artigo apresenta alguns resultados preliminares e discute os aspectos facilitadores e dificultadores desse processo.

Palavras-chave Município/Cidade Saudável; Promoção da Saúde; Qualidade de Vida 


\section{Introdução}

A qualidade de vida de uma população depende de suas condições de existência, do seu acesso a certos bens e serviços econômicos e sociais: emprego e renda, educação básica, alimentação adequada, acesso a bons serviços de saúde, saneamento básico, habitação, transporte de boa qualidade etc. É bom lembrar que o conceito de bem-estar, de qualidade de vida, varia de sociedade para sociedade, de acordo com cada cultura

Qualidade de vida e saúde são dois conceitos muito ligados. Em uma concepção moderna, saúde é o resultado de um processo de produção social que expressa a qualidade de vida de uma população. A saúde é considerada produto social, isto é, resultado das relações entre os processos biológicos, ecológicos, culturais e econômico-sociais que acontecem em determinada sociedade e que geram as condições de vida das populações (Mendes, 1996). A abordagem desse novo conceito de saúde foi reforçado pela Carta de Ottawa, elaborada na I Conferência Internacional de Promoção da Saúde realizada no Canadá, em 1986, quando afirma que as condições e os requisitos para a saúde são a paz, a educação, a moradia, a alimentação, a renda, um ecossistema estável, a justiça social e a eqüidade.

A saúde, nessa concepção mais ampla, mais do que ausência de doença é um estado adequado de bem-estar físico, mental e social que permite aos indivíduos identificar e realizar suas aspirações e satisfazer suas necessidades. À idéia de assistência, de cura, é, então, incorporado o aspecto da promoção da saúde.

A promoção da saúde é um processo, através do qual a população se capacita e busca os meios para conseguir controlar os fatores que favorecem seu bem-estar e o da comunidade ou que a podem estar pondo em risco, tornando-a vulnerável ao adoecimento e prejudicando sua qualidade de vida (Ottawa, 1986). Nas ações de promoção as pessoas são consideradas como sendo sujeitos do processo e potencialmente capazes de vir a controlar os fatores determinantes de sua saúde.

$\mathrm{Na}$ Carta de Ottawa são definidas cinco áreas operacionais para implementar a estratégia de promoção da saúde:

1) elaboração de políticas públicas saudáveis;

2) criação de ambientes favoráveis;

3) fortalecimento da ação comunitária;
4) desenvolvimento de habilidades pessoais e mudanças nos estilos de vida e

5) reorientação dos serviços de saúde.

Para operacionalizar os fundamentos da promoção da saúde no contexto local, surge o Movimento Cidades Saudáveis.

\section{A estratégia das cidades saudáveis}

O Movimento Cidade Saudável, mais que um conceito, é uma estratégia de promoção da saúde e tem como objetivo maior a melhoria da qualidade de vida da população.

A proposta de construção de cidades saudáveis surgiu em Toronto, Canadá, em 1978, quando um comitê de planejamento publicou o informe A saúde pública nos anos 80 , onde foram estabelecidas linhas de ação política, social e de desenvolvimento comunitário no nível local, como resposta aos problemas mais prevalecentes de saúde pública naquele momento. Esses delineamentos tiveram origem no Informe Lalonde (1996), que propunha um novo enfoque para a saúde pública do Canadá. Segundo esta nova concepção, a saúde estaria constituída por quatro elementos principais: a biologia humana, o meio ambiente, os hábitos ou estilos de vida e a organização dos serviços de saúde. Sob esta visão, era possível uma análise mais integral da saúde da população.

A constatação da importância dos determinantes mais gerais da saúde serviu de pano de fundo para a OMS, o governo canadense e a Associação Canadense de Saúde Pública organizarem, em 1986, a I Conferência Internacional pela Promoção da Saúde. Essa conferência teve como produto a Carta de Ottawa, que foi subscrita por 38 países.

A promoção da saúde, a partir daí, passou a ser considerada, cada vez mais, nas políticas de saúde de grande número de países, inclusive na América Latina, onde foi adotada pela Organização Mundial de Saúde/Organização Pan-Americana de Saúde - OMS/OPAS, como uma das estratégias para orientar os trabalhos de cooperação técnica na década de 1990. O Movimento Cidade Saudável surge para operacionalizar os fundamentos da promoção da saúde no contexto local.

Um município saudável, de acordo com a OPAS, é aquele em que as autoridades politicas e civis, as instituições e organizações públicas e privadas, os proprietários, empresários, 
trabalhadores e a sociedade dedicam constantes esforços para melhorar as condições de vida, trabalho e cultura da população; estabelecem uma relação harmoniosa com o meio ambiente físico e natural e expandem os recursos comunitários para melhorar a convivência, desenvolver a solidariedade, a co-gestão e a democracia (OPAS, 1996).

Segundo a OMS (1995), para que uma cidade se torne saudável ela deve esforçar-se para proporcionar:

1) um ambiente físico limpo e seguro;

2) um ecossistema estável e sustentável;

3 ) alto suporte social, sem exploração;

4) alto grau de participação social;

5) necessidades básicas satisfeitas;

6) acesso a experiências, recursos, contatos, interações e comunicações;

7) economia local diversificada e inovativa;

8) orgulho e respeito pela herança biológica e cultural;

9) serviços de saúde acessíveis a todos e

10) alto nível de saúde

A implantação e implementação de uma proposta de cidades saudáveis pressupõe um compromisso das autoridades locais com a qualidade de vida. Sem uma decisão formal de adesão e comprometimento do prefeito, responsável pela condução do processo, não é possível avançar. Além disso, o prefeito é a pessoa com maior capacidade de conseguir a comunicação e a integração entre os diversos setores locais, ponto imprescindível nesse processo.

O Movimento Cidades Saudáveis deve ser um processo permanente, não podendo estar sujeito às mudanças de governo, dependendo da vontade do prefeito de plantão. Para garantir a continuidade do movimento é preciso investir em um pressuposto básico: a participação social.

No processo de construção de uma cidade saudável, a participação significa uma postura ativa de envolvimento e co-responsabilidade dos diversos saberes, setores técnicos e segmentos sociais da população na discussão dos problemas da cidade e na tomada de decisão sobre as formas de enfrentamento dos mesmos, construindo, dessa forma, um projeto mais ampliado e real para a cidade. Além disso, é a participação que dá legitimidade política e social a esse projeto.

Através da participação, pretende-se aumentar a consciência das pessoas acerca desses problemas, em um contínuo exercício de construção de cidadania. Ao se democratizar a decisão e a gestão da cidade, está-se construindo uma nova forma de governar a cidade.

Para que o Movimento Cidade Saudável se torne efetivo é preciso que todos os setores e segmentos sociais assumam um compromisso em torno de problemas e soluções, estabelecendo-se um pacto ou contrato social em prol da melhoria da qualidade da vida.

A proposta de cidades saudáveis, como dito anteriormente, é uma estratégia de operacionalização da promoção da saúde no nível local. O seu objetivo maior é a melhoria da qualidade de vida da população. Assim, a conquista de uma vida com qualidade não passa apenas pela saúde, mas pela interação das diversas políticas sociais. Isso só é possível através da intersetorialidade.

A ação intersetorial no gerenciamento das cidades, busca superar a fragmentação das políticas, considerando o cidadão na sua totalidade. Isso exige um planejamento articulado das ações e serviços. Mas é necessário também um novo saber e um novo fazer que envolva mudanças de valores, de cultura, dentro e fora da administração municipal.

O processo de construção de municípios saudáveis, segundo a OPAS (1996), dá-se através das seguintes fases:

1) declaração pública de compromisso do governo local por avançar para a meta de ser um município saudável;

2) criação e funcionamento de um comitê intersetorial;

3) elaboração de um diagnóstico com a participação dos cidadãos e instituições locais;

4) implementação de um plano consensual estabelecendo prioridades e recursos;

$5)$ estabelecimento de um sistema de informação para o monitoramento e a avaliação no nível local.

A cidade é o local mais apropriado para o desenvolvimento dessa proposta, apresentando vários aspectos facilitadores, ao destacarse como um espaço (a) propício para promover a participação social e a integração dos diferentes setores (governamentais e não-governamentais); e (b) onde o impacto das ações governamentais sobre as condições de vida é mais claramente percebido pela população, propiciando que esta participe do processo de tomada de decisões, de um modo mais consciente e direto, colocando-se como sujeito e concretizando avanços no exercício da cidadania. 


\section{O Movimento Cidades Saudáveis no mundo e no Brasil}

O Movimento Cidade Saudável começou no Canadá em 1986 e desde então se difundiu rapidamente. Nos Estados Unidos seu desenvolvimento foi posterior. Em meados de 1990 existiam 17 redes nacionais de cidades saudáveis e uma rede internacional de língua francesa. Em seis países havia, além disso, redes subnacionais: a França tinha 7; a Espanha 2; os Estados Unidos 2, uma na Califórnia e outra em Indiana. No Canadá também existiam redes sub-nacionais: a rede de Quebec, no final de 1991, compreendia 70 municípios, denominados Villes et villages en santé, que abarcaram $40 \%$ da população total dessa província (Sotelo e Rocabalo, 1994).

No princípio dos anos 90, a OMS/OPAS tomou para si a tarefa de impulsionar o movimento na América Latina, que hoje acumula uma rica experiência. No México, em novembro de 1993, se constituiu a primeira Rede $\mathrm{Na}$ cional de Municípios pela Saúde, que conseguiu estender a idéia a 11 municípios em 1993, e a uns 150 municípios no final de 1994. Cuba iniciou com a experiência de Cienfuegos e se estendeu a outros 11 municípios, constituindo uma rede nacional de municípios saudáveis. Ainda podemos citar: Colômbia (Manizales, Cali e Versalles); Venezuela (Zamora); Chile (Valdivia); Costa Rica (Cantón de San Carlos); Panamá (San Miguelito); Guatemala (Cuilco); El Salvador (Santa Ana, Metapán e Ciudad Barrios); Honduras (Comayagua e Choluteca) e Nicarágua (León e Nandaime) - (OPAS, 1996).

A disseminação da estratégia de cidades saudáveis foi acelerada pela criação de redes, que hoje já estão estabelecidas em diversos países. Estas redes têm quatro funções básicas (Sotelo e Rocabalo, 1994):

1) difundir os conteúdos do projeto entre as autoridades municipais, os promotores potenciais e a própria comunidade, estimulando desta maneira a criação e a ampliação do movimento;

2) ser uma instância de credenciamento e de incorporação dos municípios à rede;

3) acumular e trocar experiências e informações mediante reuniões periódicas e através da utilização de diferentes meios de comunicação;

4) reconhecer e estimular aos municípios que executem seus projetos com eficiência e eficácia.
As diferentes propostas de construção de cidades saudáveis têm como características comuns o compromisso com a saúde, a tomada de decisões políticas em prol da saúde, a ação intersetorial, a participação comunitária e a busca de inovação das políticas públicas. Apesar dessas semelhanças, existem diferenças significativas entre os projetos desenvolvidos nos países de primeiro e terceiro mundo. Eles diferem-se basicamente pelo seu conteúdo programático e objetivos imediatos. Nos países desenvolvidos, a preocupação com a melhoria da qualidade de vida concentra-se em intervenções que buscam mudanças do estilo de vida, traduzidas em hábitos mais saudáveis. Enquanto que nos outros países, têm sido priorizados aspectos quantitativos de melhoria dos níveis de saúde e dos serviços, do acesso ao saneamento básico, moradia etc., ainda que sem perder de vista outras variáveis correlacionadas à qualidade de vida e à preservação do meio ambiente.

No Brasil, ainda são poucos os projetos em desenvolvimento. Motta (1998) considera a existência de 19 experiências, entretanto, sete tiveram seus processos interrompidos devido a mudança no governo municipal. São elas: São Paulo, Santos, Campinas e Diadema (SP), Céu Azul e Palmeiras (PR) e Itaguara (BA).

Outros municípios foram citados por terem participado do I Fórum Brasileiro de Municípios Saudáveis (Sobral/CE, agosto de 1998), onde foram apresentadas algumas ações que incluem orçamento participativo, ações integradas de governo, programas de saúde da família, programas de geração de emprego e renda, planos de desenvolvimento sustentável, entre outros. São eles: Belém do Pará; Niterói e Volta Redonda no Rio de Janeiro; Porto Alegre no Rio Grande do Sul; Palmas no Tocantins; Aracaju no Sergipe; Porto Seguro na Bahia e Fortaleza no Ceará. Esses municípios não desenvolvem ações direcionadas para a construção de municípios saudáveis, no entanto, essas iniciativas podem ser consideradas como prefiguradoras do Movimento.

Segundo Motta, os municípios que realizam ações direcionadas para município saudável são Crateús no Ceará e Arapiraca, Maceió e Flexeiras nas Alagoas. Podemos citar ainda Sobral e Maracanaú, no Ceará; Iraquara, na Bahia; Anadia nas Alagoas; São Paulo e Jundiaí que participaram de encontros como o V Congresso Brasileiro de Saúde Coletiva realizado em agosto de 1997 e o I Fórum Brasi- 
leiro de Municípios Saudáveis realizado em agosto de 1998.

No Estado de São Paulo, mais 23 municípios são apontados por Motta (1998) como tendo potencial para integrarem o Movimento Municípios Saudáveis, por estarem desenvolvendo trabalhos integrados, ou em rede. Essa rede de parcerias das administrações municipais entre si e com a sociedade civil começou a se estruturar, em 1997, a partir de uma proposta de Planejamento Intersetorial de Políticas Sociais feita pela Direção Regional de Saúde XX de São João da Boa Vista.

A maior dificuldade encontrada no enquadramento de municípios em uma experiência de Municípios/Cidades Saudáveis, no Brasil, é a falta de critérios ou parâmetros para a aplicabilidade do termo. Sendo assim, como aponta Motta, cada cidade tem se declarado pertencente ao movimento na medida que desenvolvem iniciativas de implementação de políticas públicas que incorporam alguns dos pressupostos delineados pelo movimento, tais como participação popular e intersetorialidade.

As poucas experiências identificadas são ainda incipientes e podem desaparecer em função da descontinuidade administrativa e da frágil participação da sociedade civil.

Essas iniciativas carecem de suporte político para se perpetuarem ao longo do tempo já que o movimento se propõe permanente. $\mathrm{Pa}$ ra tal, o I Fórum Brasileiro de Municípios Saudáveis propôs a criação de uma Rede Nacional de Municípios Saudáveis como uma estratégia que possibilite apoio e troca de experiências, dando suporte aos municípios para a consolidação do movimento.

Como forma de discutir a operacionalização e a viabilidade da proposta, é apresentada a seguir uma síntese da experiência conduzida pelo grupo da Escola de Saúde de Minas Gerais - ESMIG em duas cidades de pequeno porte no período 1996-1998.

\section{Cidades saudáveis: a experiência da ESMIG}

A Escola de Saúde de Minas Gerais criou há quase três anos um núcleo técnico que se propôs a estudar e implementar projetos ou iniciativas de cidades saudáveis em Minas Gerais. A fonte de inspiração para implantação dessa proposta foi a experiência vivida por alguns técnicos na implementação deste tipo de pro- jeto em Campinas, ainda na primeira metade da década de 1990.

Em 1994, a prefeitura de Campinas fez um convênio com a OPAS para implantar neste município o Programa da Cidade Saudável. Como parte do programa, havia um projeto específico para uma favela conhecida como Complexo São Marcos, onde seria elaborado, da forma mais participativa possível, um plano de ação intersetorial, envolvendo os diferentes setores da Secretaria Regional Norte (Educação, Saúde, Urbanismo, Ação Social, Cultura, Esporte, Lazer etc.)

Foi elaborado um plano de ação para o Complexo São Marcos, visando enfrentar dois grandes problemas apontados como prioritários pela população: a deficiência de infra-estrutura e saneamento e a questão das crianças e adolescentes em situação de rua. De acordo com o plano, a completa reurbanização do Complexo São Marcos seria possível a partir da remoção de cerca de dois terços das 1.500 famílias ali residentes e sua realocação em um novo loteamento a ser implantado em área vizinha. Para o problema das crianças e adolescentes foi planejado e executado um programa envolvendo atividades nas áreas de lazer, cultura, educação, geração de renda, trabalho com a família, recuperação de dependentes de drogas, entre outros.

O processo vivido no período de 1994 a 1996 foi bastante rico, na medida que possibilitou o desenvolvimento de um projeto realmente integrado, com ampla participação da população e dos organismos de governo e nãogovernamentais, impactando de forma positiva a qualidade de vida nessa região de Campinas. Infelizmente a implementação desse projeto foi alterada de maneira fundamental após a mudança na administração municipal.

\section{Referencial metodológico}

Para o desenvolvimento desse trabalho, tomou-se como referência o Planejamento Estratégico Situacional - PES desenvolvido pelo economista Carlos Matus. Essa metodologia de planejamento foi considerada o instrumento mais adequado para a construção de um processo de gestão democrática e participativa, pois enfatiza a complexidade da realidade abordando, além da dimensão econômica, outras dimensões como poder, organização e conhecimento. 
O conceito de situação introduzido por Matus abre o processo de planejamento a partir de novas possibilidades de compreensão da realidade, pois nos atenta para a diversidade de visões sobre os problemas e suas formas de solução, além dos conflitos que poderão existir no enfrentamento destes.

A partir da compreensão que o autor tem sobre a realidade, ele propõe o método PES como um instrumento para indivíduos ou grupos conduzirem suas ações, buscando alcançar seus objetivos. Nesse processo é fundamental analisar e construir viabilidade para as propostas de ação, considerando-se os atores envolvidos no problema, os recursos que controlam e sua motivação com relação às soluções apontadas. O PES parte do pressuposto de que um dos desafios do planejamento é construir governabilidade para viabilizar projetos. As situações de baixa governabilidade não devem constituir obstáculos para o ator que planeja, pelo contrário, devem servir como desafio a ser enfrentado.

Considera-se ainda que um outro eixo metodológico importante é o enfoque educacional que permeia todo o processo de construção da cidade saudável. Desde o início houve a preocupação de que todo o trabalho desenvolvido junto aos diferentes atores pudesse levar ao aprendizado e apropriação das tecnologias de planejamento e gestão das políticas públicas, de modo a torná-los autônomos.

Tomou-se como referência a Metodologia Problematizadora do Ensino que, mesmo não sendo dominada em profundidade, teve muitos de seus pressupostos utilizados pela equipe. Nesse método, os técnicos locais e a população são colocados como protagonistas do processo, devendo assim, ser estimulados, a todo momento, a problematizar sua realidade e instigados a buscar os conhecimentos e instrumentos necessários para intervir nos problemas levantados. Cada oficina de trabalho, cada encontro ou reunião foi cuidadosamente preparada, no sentido de propiciar um maior aprendizado e crescimento do grupo, considerando sempre, pelo menos, três aspectos básicos: o motivacional, a sua estrutura cognitiva e os seus valores.

\section{A experiência em Dionísio e São José do Goiabal}

Como mencionado anteriormente, a experiência vivida no Complexo São Marcos, em Campinas, foi a motivação para o desenvolvimento de um projeto piloto de construção de cidades saudáveis, implementada pela Escola de Saúde de Minas Gerais, em dois pequenos municípios mineiros no período de 1996 a 1998.

Para operacionalizar essa iniciativa, tomouse como pressuposto básico a idéia de que as intervenções sobre os problemas da cidade devem ser formuladas a partir de uma abordagem interdisciplinar e intersetorial, com efetiva participação da população. Além de gerar como produto um plano de ação para o enfrentamento dos problemas prioritários, a metodologia proposta seria a mais adequada, para facilitar a sua assimilação e incorporação ao cotidiano das administrações destes municípios.

A escolha dos municípios fez-se com base em critérios políticos definidos pela direção da FUNED; fato que, como veremos mais adiante, acabou trazendo dificuldades para a equipe no transcurso do projeto. Foram convidados a participar os municípios de Dionísio (9.800 habitantes) e São José do Goiabal (7.200 habitantes), situados na área de entorno do Parque Florestal do Rio Doce, na região do Vale do Aço. Nas duas cidades, vem sendo observado um decréscimo progressivo da população nas últimas três décadas, motivado sobretudo, pela falta de perspectivas de desenvolvimento econômico e social. A atividade agropecuária, vocação tradicional da região, foi perdendo espaço na medida que as terras mais férteis foram sendo adquiridas pela Companhia Belgo Mineira e ocupadas por florestas de eucaliptos. A mão-de-obra foi sendo progressivamente absorvida pela companhia, atraída pela garantia de salários regulares e outras vantagens empregatícias. Com o declínio do uso do carvão vegetal na indústria siderúrgica verificado nos últimos anos, o nível de desemprego foi crescendo e atingiu níveis alarmantes em toda a região. Atualmente, as áreas de reflorestamento ocupam quase dois terços do território desses dois municípios, deixando improdutivas as áreas férteis de baixada. Além do desemprego, persistem ainda problemas estruturais básicos, como a falta de saneamento no meio urbano e rural e as precárias condições das vias de acesso na região como um todo. 
O contato inicial para sensibilização de prefeitos, vereadores e representantes dos diversos setores municipais para a proposta de cidades saudáveis foi feito pelos escalões diretivos da ESMIG/FUNED, através da realização de grande reunião nos municípios, sem a participação da equipe técnica do projeto. $\mathrm{O}$ mal planejamento dessa atividade e o pouco entendimento da proposta por parte da direção da FUNED acabaram gerando nos participantes a falsa expectativa de que, ao projeto, estaria agregada uma grande quantidade de recursos financeiros, fato que influiu negativamente no seu desenvolvimento.

Algumas semanas após esse primeiro encontro, uma oficina de sensibilização foi então programada e realizada pela equipe técnica, com o intuito de discutir as possibilidades de melhoria das condições de vida na região com a implantação do projeto e os conceitos nucleadores do Movimento Cidades Saudáveis, quais sejam, qualidade de vida, interdisciplinaridade, intersetorialidade, participação e contrato social.

Para favorecer a ação interdisciplinar e intersetorial, o processo de participação e os compromissos políticos para sustentação do projeto, foram constituídos dois grupos comunitários em cada uma das cidades. O primeiro deles, denominado Grupo Decisório Intersetorial (GDI), tinha composição ampla e representativa dos diferentes segmentos da sociedade, podendo ser considerado a instância máxima de tomada de decisões relativas ao projeto. Já o Grupo Técnico Intersetorial (GTI), de caráter mais executivo, foi formado como subgrupo do GDI, com a responsabilidade de realizar diversas tarefas exigidas no processo, ou seja, participar das oficinas de trabalho, organizar e conduzir reuniões, coletar e analisar dados, elaborar relatórios etc. A condução do processo foi feita pelo chamado Grupo Assessor (GA), formado pelos técnicos da ESMIG, que foram os responsáveis pela sustentação teórico-metodológica.

A dinâmica dos trabalhos foi desenvolvida em um processo, onde se alternavam períodos de concentração e de dispersão. Os períodos de concentração, geralmente dois dias por mês, eram destinados à realização de encontros, seminários, oficinas e reuniões de trabalho dos grupos locais, com a presença do GA. Nesses períodos eram definidas as tarefas a serem realizadas nos períodos de dispersão, tais como trabalhos de campo, elaboração de re- latórios, preparação de seminários e desenho de projetos.

A primeira tarefa do grupo seria fazer um diagnóstico da situação dos municípios para identificação dos problemas existentes. Para esta etapa, foi utilizada a técnica da Estimativa Rápida, desenvolvida pela Organização Mundial de Saúde, que consiste em um levantamento rápido de informação, através de documentos e dados já existentes, observação ativa e entrevista com pessoas estratégicas residentes na área estudada. Essa técnica permite chegar a um diagnóstico inicial, ainda que aproximado, tendo como principais vantagens o fato de ser rápido, de baixo custo e de promover o envolvimento da população e de outros setores da região.

Em Dionísio e São José do Goiabal, os membros dos grupos locais se sentiram extremamente motivados a participar dessa etapa e, assim, elaboraram os roteiros de entrevista e observação, percorreram toda a área dos municípios, identificando e entrevistando os informantes-chave e levantaram as informações necessárias junto aos diversos órgãos em cada cidade. Em ambas, o produto foi um diagnóstico de boa qualidade, feito de forma participativa, onde foram apontados os principais problemas vividos pela população.

Diante da quantidade e diversidade de problemas levantados e da falta de recursos para o enfrentamento de todos eles, o passo seguinte foi realizar um processo de discussão e priorização desses problemas juntamente com o GDI. A falta de saneamento básico foi apontada como problema prioritário nos dois municípios, especialmente a coleta e destinação inadequada do lixo e esgoto. A má qualidade da água para consumo humano, tanto no meio urbano quanto rural, também apareceu como um grande problema para a população. No município de Dionísio foram priorizados ainda: o desemprego, a insuficiência e desorganização dos serviços de saúde e as precárias condições das vias de acesso, tanto internas como externas.

$\mathrm{Na}$ etapa seguinte, cada problema foi estudado com mais profundidade, buscando entender melhor as suas causas e conseqüências. Assim, foram organizados seminários sobre água, lixo e esgoto, contando com ampla participação da população, e com a presença de especialistas que trouxeram sua experiência, ajudando na discussão dos problemas e na busca das soluções mais adequadas de acordo com a realidade de cada cidade. 
A construção de estações simplificadas para tratamento de água, central de tratamento e compostagem de lixo, banheiros e fossas sépticas nas residências da zona rural, proteção de cisternas, preservação de mananciais de água, desenvolvimento de atividades de educação sanitária e ambiental junto à população foram algumas das soluções apontadas nos seminários. A partir daí, foram elaborados os projetos, que exigiram sempre a participação de profissional especializado para fazer o detalhamento técnico da proposta.

Seguindo a metodologia proposta no PES, o próximo passo consistiu em analisar a viabilidade dos projetos elaborados do ponto de vista dos recursos necessários para a sua implementação e da motivação dos atores que controlavam cada um desses recursos. Ao se fazer essa análise, percebeu-se que o recurso financeiro era um dos mais críticos, já que os municípios não dispunham do montante necessário para a implementação dos projetos. Além desse, também a capacidade gerencial dos municípios foi identificada como um recurso crítico fundamental para o andamento dos projetos.

Para viabilizar os recursos financeiros necessários para a implementação do plano, os projetos elaborados foram enviados ao Ministério do Planejamento/Secretaria de Políticas Urbanas, sendo aprovados e financiados com recursos do Programa de Ação Social em Saneamento - PASS. O órgão financiador estipulou uma contrapartida da ordem de $40 \%$, considerada alta para os municípios.

Como forma de compatibilizar os projetos do Movimento Cidade Saudável com as atividades desenvolvidas pelas prefeituras e melhorar a capacidade gerencial e financeira das administrações municipais, foi demandada assessoria de técnicos da Fundação João Pinheiro, órgão ligado à Secretaria Estadual de Planejamento, para avaliar aspectos relativos à organização da administração municipal.

A partir de um diagnóstico realizado pelos técnicos, chegou-se à conclusão de que, de modo geral, as prefeituras dispunham de organização formal e de perfil do quadro de recursos humanos adequados ao porte dos municípios. Seria necessário apenas trabalhar no sentido de mudar o funcionamento, o processo de trabalho dentro das prefeituras, introduzindo uma prática de descentralização e de integração intersetorial, compatibilizando o modelo de gestão municipal aos pressupostos do Projeto Cidade Saudável.
Para tanto, foi proposta a elaboração do orçamento municipal para 1999, realizado de forma intersetorial e participativa, de modo a tornar esse instrumento não uma peça de ficção e sim, um instrumento para viabilização de projetos apontados como prioritários para melhoria da qualidade da vida nessas cidades.

Foram realizados seminários setoriais com a participação do quadro de servidores municipais e do GDI, discutindo os seguintes temas: Desenvolvimento Econômico e Meio Ambiente; Educação e Cultura; Saúde e Assistência Social; Obras e Serviços Urbanos; Administração e Fazenda. Nesses seminários foram apresentadas as diretrizes de ação de governo e discutidas as alternativas de planos, projetos e atividades para cada uma dessas áreas. Em um seminário final de compatibilização, algumas dessas alternativas foram priorizadas, através de votação, conforme disponibilidade dos recursos, para estarem contempladas no orçamento municipal de 1999.

Os seminários foram momentos muito ricos pois, além de poder conhecer as propostas da prefeitura e dar sugestões para cada uma dessas áreas, os participantes puderam entender um pouco mais sobre o processo de elaboração orçamentária, receitas e despesas, legislação tributária, enfim, puderam abrir e conhecer a caixa preta da prefeitura.

Ponto fundamental no processo, foi a discussão e definição de um sistema de gerenciamento do plano. Neste caso, optou-se por um modelo coerente com a concepção de planejamento adotada, ou seja, um modelo de gestão estratégico, participativo e intersetorial. Isto significa que o gerenciamento seria feito de forma coletiva e democrática, através de colegiados.

No modelo de gestão inicialmente proposto, para cada operação seria definida uma equipe responsável e um coordenador que respondesse pela equipe. Sendo cada projeto um conjunto de operações, seria formado um colegiado composto pelos coordenadores de operação. E, por fim, o gerenciamento do plano entendido como um conjunto de projetos seria feito por um colegiado constituído pelos coordenadores de projeto. Nesse sistema, os seguintes aspectos seriam de fundamental importância: a responsabilidade, a disponibilidade de tempo e os sistemas de acompanhamento, de avaliação e de comunicação.

Essa nova forma de governar se fundamenta na efetiva delegação de poder aos coorde- 
nadores por parte dos prefeitos e na total transparência na gestão dos recursos relativos aos projetos, sem o que, esse processo poderia ser inviabilizado. A proposta busca romper com uma cultura política centralizadora e clientelista, que impera há séculos nessa região e no país de forma geral, sendo, por isso mesmo, alvo de grandes resistências por parte das elites locais.

A montagem dessa estrutura gerencial encontrou alguns entraves importantes, como a falta de recursos humanos capacitados, o trabalho voluntário da maior parte dos membros das equipes locais e o distanciamento da máquina administrativa das prefeituras em relação aos projetos elaborados.

A postura dos prefeitos em relação ao projeto como um todo apresentou grandes variações no decorrer do processo. A expectativa inicial era de que pudesse trazer uma grande quantidade de recursos financeiros e outros benefícios aos municípios. Com o passar do tempo foi ficando mais claro que o projeto não previa a transferência desse tipo de recursos, mas sim de uma cooperação técnica para transferência de metodologia de planejamento intersetorial e participativo, que permitiria elaborar projetos e captar recursos junto a outros órgãos de financiamento.

A partir da liberação dos recursos por parte da Caixa Econômica Federal, a postura transparente e descentralizada dos prefeitos voltou à sua tradicional opacidade e centralização.

O acompanhamento sistemático das atividades nos municípios foi finalizado em dezembro de 1998. Pretende-se realizar, ainda no primeiro semestre de 1999, uma avaliação sobre o projeto, abordando aspectos como estrutura, processo, resultados e satisfação da população. Sabe-se que é prematuro avaliar o impacto dos projetos neste momento, sendo assim, esse aspecto deverá ser analisado no final de 1999.

\section{Conclusão}

Embora os projetos tenham alcançado alguns resultados objetivos como a usina de reciclagem de lixo, estação de tratamento de água etc., com relação à mobilização social e ao modo de gestão da cidade os resultados não foram satisfatórios. Estes são os dois aspectos mais importantes a serem aprimorados do ponto de vista metodológico.
Quanto à mobilização social, o objetivo foi desencadear nos municípios um amplo movimento que se traduziria em um pacto de toda a sociedade e administração pública pela melhoria da qualidade de vida. Entretanto, o envolvimento da comunidade não se deu de forma engajada, massiva e atuante como esperado. A explicação para isso talvez esteja na insuficiência das estratégias adotadas e na forma em que historicamente se dão as relações entre estado e sociedade.

Do ponto de vista das estratégias adotadas no desenvolvimento do projeto, acreditava-se que um processo de planejamento estratégico desencadeado de forma participativa, envolvendo o maior número possível de pessoas da comunidade nos diversos momentos do processo, por si só, fosse capaz de produzir mobilização social. A prática mostrou que não. Pelo contrário, o excesso de formalismo na elaboração do plano de ação, pode levar a uma desmobilização em torno do projeto. É preciso pensar continuamente estratégias de comunicação que levem à mobilização.

Por outro lado, a relação entre o poder público e sociedade, nos dois municípios, é caracterizada fortemente pelo clientelismo político, levando a população a uma postura passiva e desconfiada. Ela não se considera capaz de provocar e construir mudanças, não acredita na efetividade de sua participação.

Do ponto de vista da transformação do modo de gestão da cidade, os resultados foram bastante insatisfatórios. A possibilidade de implementar com sucesso a estratégia de cidade saudável pressupõe, fundamentalmente, uma mudança no modo de governar a cidade, ou seja, uma gestão democrática, transparente, integradora e que busque, junto com a população, definir e implementar políticas e atitudes saudáveis.

Os municípios de Dionísio e São José do Goiabal não fogem à tradição política brasileira, que se funda no clientelismo político, na centralização e opacidade administrativa, na fragmentação das ações e na inexistência de tradição em planejamento integrado e participativo, fatores que dificultam a implementação desse tipo de iniciativa.

Em São José do Goiabal, a administração pública, representada pelo prefeito e funcionários, esteve durante a maior parte do processo pouco integrada ao movimento, dificultando assim a incorporação dos valores fundamentais do movimento. 
Também em Dionísio, apesar da presença constante do prefeito durante todo o processo, os ideais do movimento também não contagiaram a administração a ponto de transformar a gestão municipal. Os técnicos da prefeitura somente se integraram ao projeto após a elaboração do orçamento de 1999. Com a liberação de recursos para as obras priorizadas, aumentou ainda mais a distância entre o movimento e a administração municipal, o que acabou levando ao rompimento da coordenação do GTI com o prefeito.

O fato da iniciativa do projeto ter sido da Fundação Ezequiel Dias, sem nenhuma demanda nas cidades que apontasse no sentido da proposta de cidade saudável, favoreceu o descompromisso das prefeituras com essa nova proposta de governo. Os prefeitos aceitaram prontamente o projeto visando apenas os recursos financeiros que o projeto poderia trazer e, obviamente, os votos que poderiam capitalizar com as obras que seriam feitas. O resultado foi um total descompasso entre a administração e a coordenação do GTI, gerando grandes conflitos de interesses.

Mas, certamente, essa iniciativa produziu alguns bons frutos. A mobilização das pessoas no sentido de identificar e buscar soluções para os seus problemas prioritários, como no diagnóstico (Estimativa Rápida), nos seminários para discussão dos problemas e nos seminários do orçamento participativo, foi um momento muito fecundo para resgatar a cidadania e possibilitar a reflexão sobre a qualidade da vida nessas cidades.

\section{Referências bibliográficas}

Carta de Ottawa. Ministério da Saúde, Brasília.

Junqueira LAP 1997. Novas formas de gestão na saúde: descentralização e intersetorialidade. Saúde e Sociedade. Faculdade de Saúde Pública da Universidade de São Paulo e Associação Paulista de Saúde Pública. v. 6, n. 2 (ago/dez 1997), São Paulo.

Malik AM 1997. Cidades saudáveis - estratégia em aberto. Saúde e Sociedade. Faculdade de Saúde Pública da Universidade de São Paulo e Associação Paulista de Saúde Pública. v. 6, n. 2 (ago/dez 1997), São Paulo.

Mendes EV 1996. Um novo paradigma sanitário: a produção social da saúde, pp. 233-300. In Mendes EV. Uma Agenda para a Saúde. Ed. Hucitec, São Paulo.

Motta RMM, Westphal MF, Bogus CM e Caricari AM 1998. Panorama das Cidades/Municípios Saudáveis no Brasil. Faculdade de Saúde Pública USP/Organização Pan-americana de Saúde, São Paulo.
A experiência na elaboração de projetos e mobilização de recursos financeiros, políticos, cognitivos e organizativos para construir viabilidade, vivenciada por alguns técnicos e lideranças locais, certamente são habilidades que, uma vez adquiridas, poderão ser úteis na elaboração de futuros projetos da comunidade.

Da mesma forma, a abertura da caixa preta da prefeitura municipal durante o processo de discussão do orçamento foi um momento ímpar para que as lideranças comunitárias e a população em geral pudessem entender o funcionamento da máquina administrativa, decifrar o significado do orçamento, conhecer as fontes de recursos disponíveis e a natureza das despesas da prefeitura.

Embora o projeto não tenha alcançado os resultados desejados, acredita-se que com a superação dos problemas metodológicos apontados, a proposta Cidade Saudável tenha se configurado numa estratégia capaz de operacionalizar a promoção da saúde, tirando-a do nível apenas do discurso e das intenções.

Acima das questões metodológicas colocadas, o ponto fundamental para o êxito desta proposição é a existência de uma efetiva comunhão de valores entre a administração municipal e a sociedade, uma disposição e uma vontade política para superar os problemas e melhorar a qualidade de vida nas cidades. Sem isso, provavelmente, esta estratégia fracassará.

A realização de uma avaliação sistematizada da experiência permitirá uma análise mais profunda dos aspectos metodológicos e conjunturais que permearam o desenvolvimento destas experiências.

OMS 1995. Vinte pasos para formular un proyeto de ciudades sanas. Washington.

OPAS 1996. El Movimiento de Municipios Saludables: una Estrategia para la Promoción de la Salud en América Latina, v. 96-14, abril.

Sotelo JM e Rocabalo F 1994. Salud desde el municipio: una estrategia para el desarrollo. OPS/OMS, Division of Health Promotion and Protection (HPP), México. júlio-agosto, vol. 36. no 4.

Universidade Catolica de Manizales 1994. Promoción y protección de la salud: ciudades saludables. Manizales: Centro de Comunicación Social en Salud. $18 \mathrm{p}$.

Westphal MF 1997. Municípios saudáveis: aspectos conceituais. Saúde e Sociedade. Faculdade de Saúde Pública da Universidade de São Paulo e Associação Paulista de Saúde Pública. v. 6, n. 2 (ago/dez 1997), São Paulo. 